\title{
Desempenho de sistemas de irrigação por aspersão convencional na cultura do milho (Zea mays L.) ${ }^{1}$
}

\author{
Performance of systems of irrigation for conventional \\ aspertion in maize (Zea mays L.) \\ Camila Aparecida da Silva Martins ${ }^{2}$, Edvaldo Fialho dos Reis ${ }^{3}$, \\ Renato Ribeiro Passos ${ }^{4}$, Giovanni de Oliveira Garcia ${ }^{5}$
}

\begin{abstract}
RESUMO
Na agricultura irrigada a inadequada uniformidade de aplicação de água em sistemas de irrigação proporciona excesso da mesma em parte da área cultivada e déficit em outra, reduzindo a disponibilidade de água à cultura do milho e aumentando o custo de produção. Este trabalho teve o objetivo de avaliar, em nível de campo, o comportamento de sistemas de irrigação por aspersão convencional no Sul do Estado do Espírito Santo. Foram escolhidos aleatoriamente, cinco projetos de irrigação por aspersão convencional na cultura do milho destinado a alimentação animal. Em cada projeto, realizou-se o teste de uniformidade de aplicação de água para a determinação dos coeficientes de uniformidades mais utilizados (Coeficiente de Uniformidade de Christiansen, Coeficiente de Uniformidade Estatística e Coeficiente de Uniformidade de Distribuição) e da eficiência de aplicação de água. Os resultados das avaliações realizadas nos sistemas de irrigação mostram que $60 \%$ dos projetos de irrigação por aspersão convencional avaliados apresentam baixa uniformidade de aplicação de água; a lâmina aplicada no período avaliado é superior à lâmina real necessária à planta; e que a média da eficiência de aplicação (Ea) nos projetos é de $71,88 \%$, ficando abaixo de $75 \%$, preconizado pela literatura como o mínimo aceitável.
\end{abstract}

Palavras-chave: coeficientes de uniformidade, características hidráulicas, grãos.

\begin{abstract}
In irrigated agriculture inadequate uniformity of water application in irrigation systems provides an excess of one part of the acreage and a deficit in another, reducing the availability of water to corn and increasing the cost of production. The objective of this study was to evaluate in the field the performance of systems for conventional sprinkler irrigation in the south of the state of Espirito Santo. Five irrigation projects with conventional sprinkler irrigation were chosen randomly. Each project was tested for uniformity of application of water by determining several coefficients of uniformity (Coefficient of Uniformity of Christiansen, Coefficient of Statistical Uniformity and Coefficient of Uniformity of Distribution), and for the efficiency of application of water. The results show that $60 \%$ of the irrigation projects with conventional sprinkler irrigation evaluated presented low uniformity of application of water; that the depth of water applied in the appraised period is superior to the required depth for the plant; and that the average of the application efficiency in the projects was $71.88 \%$, below the $75 \%$ recommended in the literature as the acceptable minimum.
\end{abstract}

Key words: coefficients of uniformity, hydraulic characteristics. grains.

\section{Introdução}

A agricultura irrigada tem sido uma importante estratégia para otimização da produção mundial de alimentos, gerando desenvolvimento sustentável no campo, com geração de empregos e renda de forma estável (Mantovani; Bernardo; Palaretti, 2009). Mas, a água, que é o principal fator na irrigação, tem se tornado cada vez mais limitante por causa da implementação inadequada de novas

1 Parte da Dissertação de Mestrado apresentada pela primeira autora a Universidade Federal do Espírito Santo/UFES para obtenção do título de Mestre em Produção Vegetal.

2 Doutoranda em Produção Vegetal, Programa de Pós-Graduação em Produção Vegetal, CCAUFES, Alegre-ES.

E-mail: camila.cca@ hotmail.com.

3 Engenheiro Agrícola, Prof. Dr. Associado 1, Departamento de Engenharia Rural, CCAUFES, Alegre-ES.

4 Engenheiro Agrônomo, Prof. Dr. Adjunto 2, Departamento de Produção Vegetal, CCAUFES, Alegre-ES.

5 Engenheiro Agrônomo, Prof. Dr. Adjunto 1, Departamento de Engenharia Rural, CCAUFES, Alegre-ES.

Fecha de Recepción: 26 Julio, 2010.

Fecha de Aceptación: 09 Febrero, 2011. 
áreas irrigadas ou por falta da disponibilidade de recursos hídricos, devido à poluição ambiental. Por isso, torna-se imprescindível a adoção de medidas que possibilite o uso adequado dos recursos hídricos disponíveis (Bernardo; Soares; Mantovani, 2006).

A avaliação do desempenho de sistemas de irrigação está ligada a diversos parâmetros definidos em determinações de campo, tais como vazão, tempo de irrigação e uniformidade de aplicação de água, nos quais são considerados fundamentais para tomadas de decisões em relação ao diagnóstico do sistema. No entanto, a avaliação de sistemas de irrigação é uma prática que os irrigantes não têm dado importância, porque mesmo tendo acesso à tecnologia, muitos não a utilizam de forma adequada, por falta de conhecimento e até mesmo por falta de orientação técnica (Silva; Silva, 2005).

O sistema de irrigação por aspersão convencional é muito utilizado em pequenas e médias propriedades, devido a sua ampla aplicabilidade. Nesse sistema, a água é aspergida sobre as plantas, simulando uma precipitação natural (chuva), por meio de vários aspersores que funcionam simultaneamente numa mesma linha lateral. Esse sistema tem um consumo médio de energia e muita exigência em mão-de-obra para mudanças de linhas. Além disso, apresenta valores de eficiência de uniformidade da ordem de 75 a 90\% (Mantovani; Bernardo; Palaretti, 2009).

Segundo Bernardo; Soares; Mantovani (2006) o Coeficiente de Uniformidade de Christiansen (CUC), proposto por Christiansen (1942), o Coeficiente de Uniformidade Estática (Us), estabelecido por Wilcox e Swailes (1947) e o Coeficiente de Uniformidade de Distribuição (CUD) elaborado por Criddle et al. (1956), são os três coeficientes mais utilizados para determinação da uniformidade de aplicação e distribuição de água de um sistema de irrigação por aspersão, na superfície do solo.

O milho (Zea mays L.), grão de relevante importância econômica e social no Brasil, apresenta-se como alternativa para a alimentação animal na região Sudeste do país e no Sul do Estado do Espírito Santo. O desenvolvimento desta cultura é influenciado pela quantidade de água no solo, pois tanto o déficit hídrico quanto o excesso de água na área de cultivo reduz a produtividade e a qualidade do produto. Neste sentido, a irrigação é um dos tratos culturais que mais favorece o desenvolvimento produtivo das culturas de importância socioeconômica do país (Fancelli; Dourado Neto, 2000).
Diante do exposto, este trabalho teve o objetivo de avaliar o desempenho de sistemas de irrigação por aspersão convencional na cultura do milho (Zea mays L.), por meio da determinação da uniformidade e eficiência de aplicação de água nas condições edafoclimáticas da região Sul do Estado do Espírito Santo.

\section{Material e Métodos}

Este trabalho foi desenvolvido em cinco propriedades produtoras de milho destinado á alimentação animal, localizadas na região Sul do Estado do Espírito Santo, no período de maio a outubro de 2008, onde foram avaliados cinco projetos de irrigação por aspersão convencional. A seleção dos projetos e sua localização basearam-se em levantamentos realizados na região por técnicos do Instituto Capixaba de Pesquisa, Assistência Técnica e Extensão Rural-INCAPER, em 2007, seguindo critério quanto o tamanho da área irrigada e o sistema de irrigação utilizado. Em cada projeto, realizou-se o teste de uniformidade de aplicação de água, para a determinação dos coeficientes de uniformidade mais usuais e da eficiência de aplicação de água.

O clima da região é classificado como Cwa, segundo o sistema Köppen, apresentando chuvas no verão e seca no inverno, com precipitação média anual de $1200 \mathrm{~mm}$ e temperatura média anual de $23^{\circ} \mathrm{C}$. O relevo predominante na região é montanhoso.

Na Tabela 1, estão apresentadas a localização, o tempo de uso, a idade da cultura do milho irrigado e a área irrigada dos cinco projetos de irrigação por aspersão convencional avaliados no Sul do Estado do Espírito Santo.

As avaliações da uniformidade de aplicação de água dos projetos de irrigação por aspersão convencional foram realizadas com base na metodologia de Christiansen (1942) apresentada por Bernardo; Soares; Mantovani (2006).

Durante o teste, mediu-se a vazão no bocal, de maior e de menor diâmetro, do aspersor, a pressão de serviço do aspersor e o volume ou lâmina d'água coletada, em cada "pluviômetro", no final do teste.

Para a medição de vazão nos sistemas de irrigação, foi coletado em cada aspersor, previamente selecionado, o volume aplicado em um tempo de três minutos, com auxílio de cronômetro, mangueiras, coletores e proveta graduada. Utilizando um manômetro com tubo de Pitot, avaliou-se a pressão de serviço (Ps) do aspersor em funcionamento. 
Tabela 1

Localização, tempo de uso, idade da cultura do milho irrigado e área irrigada dos projetos de irrigação por aspersão convencional avaliados.

\begin{tabular}{llccc}
\hline Projeto & Localização & $\begin{array}{c}\text { Tempo de Uso } \\
\text { (meses) }\end{array}$ & Idade da Cultura (meses) & Área Irrigada (ha) \\
\hline 1 & Alegre & 14 & 2 & 1 \\
2 & São José do Calçado & 32 & 2,5 & 3 \\
3 & São José do Calçado & 18 & 3 & 3 \\
4 & São José do Calçado & 9 & 3 & 2 \\
5 & São José do Calçado & 9 & 2,5 & 3 \\
\hline
\end{tabular}

A uniformidade de aplicação de água foi estimada, utilizando-se os dados de precipitação de cada um dos projetos, em função do Coeficiente de Uniformidade de Christiansen (CUC), determinado pela equação (1), do Coeficiente de Uniformidade Estatística (Us), determinado pela equação (2) e do Coeficiente de Uniformidade de Distribuição (CUD), determinado pela equação (3).

A interpretação dos valores dos coeficientes de uniformidade (CUC, Us e CUD) baseou-se na metodologia apresentada por Mantovani (2001) que está apresentada na Tabela 2.

$$
\begin{gathered}
C U C=\left\{1-\frac{\sum_{i=l}^{n}\left|L_{i}-L_{m}\right|}{N L_{m}}\right\} 100 \\
U s=100\left\{1-\frac{S_{d}}{L_{m}}\right\} \\
C U D=\frac{L_{q}}{L_{m}} 100
\end{gathered}
$$

em que:

CUC $=$ Coeficiente de Uniformidade de Christiansen, em \%; $\mathrm{L}_{\mathrm{i}}=$ Lâmina obtida no coletor "ii", mm; $\mathrm{L}_{\mathrm{m}}$ = Lâmina média de todas as observações, $\mathrm{mm}$; e $\mathrm{N}$ = Número de coletores.

Us = Coeficiente de Uniformidade Estatística, em $\% ; \mathrm{Sd}=$ desvio-padrão dos dados de precipitação; e $\mathrm{L}_{\mathrm{m}}=$ média das precipitações, $\mathrm{mm}$.

CUD = Coeficiente de Uniformidade de Distribuição, em \%; $\mathrm{L}_{\mathrm{q}}=$ média de $25 \%$ das observações com menores valores, $\mathrm{mm}$; $\mathrm{e}_{\mathrm{m}}=$ lâmina média de todas as observações, $\mathrm{mm}$.
Tabela 2

Classificação dos valores do desempenho de sistemas de irrigação por aspersão convencional em função do Coeficiente de Uniformidade de Christiansen (CUC), do Coeficiente de Uniformidade Estatística (Us) e do Coeficiente de Uniformidade de Distribuição (CUD).

\begin{tabular}{lccc}
\hline Classificação & CUC $(\%)$ & Us $(\%)$ & CUD $(\%)$ \\
\hline Excelente & $>90$ & $90-100$ & $>84$ \\
Bom & $80-90$ & $80-90$ & $68-84$ \\
Razoável & $70-80$ & $70-80$ & $52-68$ \\
Ruim & $60-70$ & $60-70$ & $36-52$ \\
Inaceitável & $<60$ & $<60$ & $<36$ \\
\hline
\end{tabular}

Fonte: Mantovani 2001.

Em cada projeto, as amostras de solo foram retiradas ao acaso em cinco pontos de cada área irrigada nas profundidades de $0,00-0,40 \mathrm{~m}$ para avaliação do manejo de irrigação nos sistemas de irrigação por aspersão convencional. Para cada área em estudo, a amostragem de solo foi realizada antes da irrigação, coletando-se amostras deformadas com o auxílio de um trado tipo holandês, as amostras foram acondicionadas em recipientes vedados, para determinação da umidade atual do solo pelo método termogravimétrico, conforme preconizado pela EMBRAPA (1999).

Simultaneamente à determinação da umidade do solo, foram coletadas subamostras em cada um dos locais amostrados, que depois foram misturadas, a fim de formar uma amostra composta para a determinação da densidade do solo pelo método da proveta; da capacidade de campo com o auxílio do extrator de Richards e da análise granulométrica pelo método da pipeta através da agitação lenta, de acordo com a EMBRAPA (1999). Posteriormente, realizaram-se as análises físicas do solo (densidade do solo, análise granulométrica, umidade atual do solo) e a análise hídrica (capacidade de campo) do 
solo das áreas irrigadas para avaliação do desempenho dos sistemas de irrigação em estudo.

A profundidade efetiva do sistema radicular das culturas irrigadas para determinação da lâmina de irrigação real necessária foi definida a partir de valores citados por Manfron et al. (2003) e confirmados em campo através de observações. Foram utilizados valores de $0,20 \mathrm{~m}$ no projeto 1 , seguidos por $0,25 \mathrm{~m}$ nos projetos 2 e 5 e de $0,30 \mathrm{~m}$ para os projetos $3 \mathrm{e} 4$, porque devido aos estádios de desenvolvimento inicial e vegetativo das culturas, $80 \%$ das raízes se concentram nessas profundidades.

A lâmina de irrigação real necessária para os projetos de irrigação por aspersão convencional foi determinada pela equação (4):

$$
I R N=\frac{(C C-U a}{10} D S Z
$$

em que:

IRN = irrigação real necessária, $\mathrm{mm} ; \mathrm{CC}=$ teor de umidade na capacidade de campo, $\%$ em peso; $\mathrm{Ua}=$ teor de umidade do solo antes da irrigação, \% em peso; Ds = densidade aparente ou massa específica do solo, $\mathrm{g} \mathrm{cm}^{-3}$; e $\mathrm{Z}=$ profundidade efetiva do sistema radicular, $\mathrm{cm}$.

Após a determinação da IRN real, determinou-se a lâmina aplicada durante a irrigação por meio da expressão (5):

$$
L a p l=\frac{1000 Q T}{S_{1} S_{2}}
$$

em que:

Lapl = lâmina aplicada, mm; $\mathrm{Q}=$ vazão do sistema, $\mathrm{m}^{3} \mathrm{~h}^{-1} ; \mathrm{T}=$ Tempo, $\mathrm{h} ; \mathrm{S} 1=$ espaçamento entre posições ao longo da linha lateral, m; e S2 = espaçamento entre linhas laterais, $\mathrm{m}$.

Além da Lapl, determinou-se: a lâmina média coletada $(\mathrm{mm})$, que é a média aritmética das lâminas coletadas no teste de uniformidade realizado no campo; a lâmina armazenada na zona radicular ( $\mathrm{mm}$ ), que se refere à parcela da lâmina aplicada que fica retida na zona radicular; a lâmina deficitária $(\mathrm{mm})$ que é a média da diferença entre lâmina armazenada na zona radicular e a IRN. Posteriormente, estimou-se a lâmina percolada (mm), ou seja, a média do excesso da lâmina aplicada em relação à IRN.
Após a determinação dos coeficientes de uniformidade e das lâminas, realizou-se a avaliação do desempenho dos sistemas de irrigação por aspersão convencional através da determinação dos seguintes parâmetros técnicos: porcentagem de área adequadamente irrigada (Pad), eficiência em potencial de aplicação de água (Epa), segundo Bernardo (1995), coeficiente de déficit (Cd), perdas por percolação (Pper), eficiência de condução (Ec), eficiência de distribuição de projeto (EDpad), eficiência de irrigação para área adequadamente irrigada (Eipad) e eficiência de aplicação (Ea).

A eficiência em potencial de aplicação de água foi calculada segundo Bernardo (1995), através da equação (6):

$$
E p a_{\text {Bernardo }}=\frac{\text { Lmcol }}{\text { Lapl }} 100
$$

em que:

$\mathrm{Epa}_{\text {Bernardo }}=$ eficiência em potencial de aplicação de água, segundo Bernardo (1995), \%; Lmcol = lâmina média coletada, mm; e Lapl = lâmina aplicada, mm.

Em seguida, efetuou-se o cálculo do coeficiente de déficit, que é a razão entre a lâmina de água deficitária (Ldef, mm) e a lâmina de irrigação real necessária (IRN, mm), através da expressão (7):

$$
C d=\frac{L d e f}{I R N} 100
$$

em que:

$\mathrm{Cd}=$ coeficiente de déficit, \%; Ldef = lâmina deficitária, mm; e IRN = irrigação real necessária, mm.

As perdas por percolação, que é a razão entre lâmina percolada e lâmina média coletada durante o teste de uniformidade, foi estimada pela equação (8):

$$
P p=\frac{\text { Lper }}{\text { Lmcol }} 100
$$

em que:

$\mathrm{Pp}=$ perdas por percolação, \%; Lper = lâmina percolada, $\mathrm{mm} ; \mathrm{e} \mathrm{Lmcol} \mathrm{=} \mathrm{lâmina} \mathrm{média} \mathrm{coletada,} \mathrm{mm.}$

A Eficiência de condução (Ec) foi estimada por meio da equação (9), que relaciona o volume de entrega na parcela agrícola e o volume derivado captado no bombeamento. 


$$
E c(\%)=\frac{\text { Vol. Entrega }}{\text { Vol. Derivado }} 100
$$

A eficiência de distribuição de projeto para uma porcentagem de área adequadamente irrigada (EDpad) foi estimada pela equação (10):

$$
\begin{aligned}
& \text { EDpad }=100+\left(606-24,9 P a d+0,349 P^{2} d^{2}\right. \\
& \left.-0,00186 P^{3} d^{3}\right)(1-(C U C / 100))
\end{aligned}
$$

em que:

EDad = eficiência de distribuição de projeto, \%; $\mathrm{Pad}=$ porcentagem de área adequadamente irrigada, \%. É escolhida pelo usuário conforme o nível de uniformidade que deseja, por exemplo, $80 \%$.

A eficiência de irrigação para a área adequadamente irrigada que é o valor a ser utilizado na estimativa da lâmina a ser aplicada em uma condição de manejo adequado do sistema, com a aplicação de uma lâmina que possibilite atingir uma porcentagem de área adequadamente irrigada preestabelecida. Foi estimada pela expressão (11):

$$
\text { Eipad }=\text { EDpa Epa } a_{\text {Keller e Bliesner }} \text { Ec } 100
$$

em que:

Eipad = eficiência de irrigação para área adequadamente irrigada de projeto, \%; EDpa = eficiência de distribuição para uma porcentagem de área adequadamente irrigada, decimal; Epa $_{\text {Keller e Bliesner }}=$ eficiência potencial de aplicação de água, segundo Keller e Bliesner (1990), decimal; e Ec = eficiência de condução, decimal.

E por último, determinou-se a eficiência de aplicação de água através da equação (12), que relaciona o volume de água armazenado no solo com o volume de água aplicado na área.

$$
E a(\%)=\frac{\text { Vol. Amazenado }}{\text { Vol. Aplicado }} 100
$$

\section{Resultados e Discussão}

Os valores do Coeficiente de Uniformidade de Christiansen (CUC), do Coeficiente de Uniformidade Estatística (Us), do Coeficiente de Uniformidade de Distribuição (CUD) e as respectivas classificações dos valores dos coeficientes de uniformidade dos projetos de irrigação por aspersão convencional avaliados estão apresentados na Tabela 3.

Observando os valores de CUC para o sistema de irrigação em estudo (Tabela 3), nota-se que os projetos avaliados apresentam valores inferiores a 90\%, o que não é recomendado para culturas com alto valor comercial (BERNARDO; SOARES; MANTOVANI, 2006). Apenas $40 \%$ dos projetos avaliados apresentaram valores de CUC entre $80 \mathrm{e}$ $90 \%$, o que é classificado como bom, e três projetos, $60 \%$ do total, apresentaram valores inferiores a $80 \%$. Portanto, os projetos avaliados apresentam resultados de uniformidade para o Coeficiente de Uniformidade de Christiansen (CUC) considerados inadequados para as culturas agrícolas. Em função da falta de conhecimento e de orientação técnica sobre o manejo da irrigação, os irrigantes da região praticam a irrigação por aspersão convencional sem técnica de manejo e sem a manutenção periódica dos equipamentos.

Analisando o valor do Coeficiente de Uniformidade Estatística (Us) obtido nesses projetos, nota-se que apenas $20 \%$ deles apresentaram valores considerados bons para sistemas de irrigação por aspersão convencional. Com relação aos valores de CUD, verifica-se que $60 \%$ dos projetos avaliados apresentaram valores de coeficiente de uniformidade de distribuição de água abaixo do valor recomendado para sistemas de irrigação por aspersão

Tabela 3. Valores do Coeficiente de Uniformidade de Christiansen (CUC), Coeficiente de Uniformidade Estatística (Us), Coeficiente de Uniformidade de Distribuição (CUD) e respectivas classificações dos coeficientes, dos sistemas de irrigação por aspersão convencional avaliados.

\begin{tabular}{lcccccc}
\hline Projeto & CUC $(\%)$ & Classificação & Us $(\%)$ & Classificação & CUD (\%) & Classificação \\
\hline 1 & 81,94 & Bom & 72,39 & Razoável & 76,24 & Bom \\
2 & 71,11 & Razoável & 65,52 & Ruim & 58,23 & Razoável \\
3 & 64,17 & Ruim & 56,18 & Inaceitável & 43,61 & Ruim \\
4 & 86,09 & Bom & 82,51 & Bom & 74,80 & Bom \\
5 & 70,13 & Ruim & 63,19 & Ruim & 51,69 & Ruim \\
\hline
\end{tabular}


convencional, que de acordo com a classificação apresentada por Mantovani (2001) é de 68\%, o que induz maior consumo de água, de energia e menor rendimento das culturas. Resultados semelhantes foram obtidos por Bonomo et al. (2008) em sistema de irrigação por aspersão fixa no Norte Capixaba.

Os valores de CUC, Us e CUD encontrados são considerados baixos quando comparados com os resultados obtidos por Alencar et al. (2007). A baixa uniformidade de aplicação de água do sistema de irrigação avaliado se deve em grande parte ao mau dimensionamento do projeto e a ausência de manejo do sistema. Geralmente, reduzidos valores de uniformidade determinam maiores consumo de água e energia, maiores perdas de nutrientes por deflúvio superficial e percolação profunda ao mesmo tempo em que podem apresentar plantas com déficits hídricos, em proporção significativa da área irrigada. Resultados semelhantes foram obtidos por Souza et al. (2008), em sistema de irrigação por aspersão convencional, na região Noroeste do Estado do Paraná.

De acordo com o triângulo textural apresentado pela EMBRAPA (2006), os solos das propriedades que utilizam o sistema de irrigação por aspersão convencional, na profundidade de $0,00-0,40 \mathrm{~m}$ foram classificados como solos de textura média, por possuírem na composição granulométrica menos de 35\% de argila e mais de $15 \%$ de areia. Por isso, o manejo da irrigação nesses solos deve ser cuidadoso, considerando a média capacidade de retenção de água. Considerando essa classificação textural, foram utilizadas para a determinação da capacidade de campo dos solos, valores de umidades equivalentes à tensão de $0,1 \mathrm{~atm}$.

$\mathrm{Na}$ Tabela 4 são apresentados os valores de capacidade de campo $(\mathrm{Cc})$, umidade atual do solo (Ua) e densidade aparente do solo (Ds), dos solos onde estão instalados os projetos de irrigação avaliados. Observa-se que a capacidade de campo variou de
18,48 a $26,57 \%$, a umidade atual do solo variou de 13,64 a $22,64 \%$ e a densidade do solo entre 1,00 e $1,28 \mathrm{~g} \mathrm{~cm}^{-3}$.

Na Tabela 5 estão apresentados os valores de irrigação real necessária (IRN), lâmina aplicada (Lapl), lâmina média coletada durante a realização do teste de uniformidade de aplicação de água em campo (Lmcol), lâmina armazenada na zona radicular (Larm), lâmina deficitária (Ldef) e lâmina percolada (Lper), nos projetos que utilizam sistema de irrigação por aspersão convencional.

Tabela 4

Valores de Capacidade de campo (Cc), Umidade atual do solo (Ua) e Densidade do solo (Ds) dos solos onde estão instalados os sistemas de irrigação avaliados.

\begin{tabular}{lccc}
\hline Projeto & Cc (\% peso) & Ua (\% peso) & Ds $\left(\mathrm{g} \mathrm{cm}^{-3}\right)$ \\
\hline 1 & 24,81 & 20,07 & 1,22 \\
2 & 20,85 & 16,66 & 1,04 \\
3 & 24,81 & 21,27 & 1,03 \\
4 & 26,57 & 22,64 & 1,02 \\
5 & 24,65 & 20,18 & 1,12 \\
\hline
\end{tabular}

Com os dados da Tabela 4 realizou-se o cálculo da IRN (Tabela 5), que variou de 10,89 a 12,52 mm nos projetos avaliados, em função do teor de umidade no solo, que diferiu de um projeto para o outro, devido à composição granulométrica dos solos dos projetos que utilizam sistema de irrigação por aspersão convencional. Tendo em vista que os solos onde estão instalados os projetos avaliados apesar de possuírem a mesma textura, se diferem quanto às proporções das frações de areia, silte e argila. Podendo-se inferir que nos solos em estudo o teor de umidade tende a ser elevado porque esses solos são compactados pelo trânsito de máquinas agrícolas.

A Ds influencia a IRN porque reflete o arranjamento das partículas do solo, que por sua vez

Tabela 5. Irrigação Real Necessária (IRN), Lâmina aplicada (Lapl), Excesso de água aplicada, Lâmina média coletada (Lmcol), Lâmina armazenada na zona radicular (Larm), Lâmina deficitária (Ldef) e Lâmina percolada (Lper) nos projetos que utilizam sistema de irrigação por aspersão convencional.

\begin{tabular}{lccccccc}
\hline Projeto & $\begin{array}{c}\text { IRN } \\
(\mathrm{mm})\end{array}$ & $\begin{array}{c}\text { Lapl } \\
(\mathrm{mm})\end{array}$ & $\begin{array}{c}\text { Excesso } \\
(\%)\end{array}$ & $\begin{array}{c}\text { Lmcol } \\
(\mathrm{mm})\end{array}$ & $\begin{array}{c}\text { Larm } \\
(\mathrm{mm})\end{array}$ & $\begin{array}{c}\text { Ldef } \\
(\mathrm{mm})\end{array}$ & $\begin{array}{c}\text { Lper } \\
(\mathrm{mm})\end{array}$ \\
\hline 1 & 11,57 & 16,62 & 43,65 & 12,54 & 9,48 & 2,09 & 2,54 \\
2 & 10,89 & 12,96 & 19,01 & 11,83 & 10,48 & 0,42 & 3,99 \\
3 & 10,94 & 13,68 & 25,05 & 11,77 & 10,62 & 0,32 \\
4 & 12,03 & 18,72 & 55,61 & 15,27 & 11,79 & 0,24 & 4,58 \\
5 & 12,52 & 13,80 & 10,22 & 12,26 & 11,18 & 1,34 & 3,38 \\
\hline
\end{tabular}


define as características do sistema poroso. Por isso, o aumento excessivo da Ds acarreta redução do volume total de poros, bem como a redução da permeabilidade e da infiltração de água, quebra dos agregados e aumento da resistência mecânica à penetração, o que ocasiona prejuízo à qualidade física do solo (MARTINS et al., 2007).

Pela Tabela 5, nota-se que em todos os sistemas de irrigação por aspersão convencional em estudo, a lâmina de irrigação aplicada (Lapl) foi maior que a lâmina real necessária (IRN), isto indica que todos os projetos em estudo aplicavam água em excesso, apresentando, portanto, baixa eficiência de aplicação, o que difere dos resultados obtidos por Souza et al. (2008), em sistema de irrigação por aspersão convencional instalado na Vila Rural Flor do Campo, localizada na região Noroeste do Estado do Paraná, onde a lâmina aplicada foi inferior à lâmina real necessária, indicando que a irrigação foi deficitária.

A lâmina média coletada (Lmcol) durante o teste de uniformidade de aplicação variou de 11,77 a 15,27 mm nos projetos avaliados. Nota-se que o projeto 4 apresentou o maior valor e o projeto $3 \mathrm{o}$ menor valor. Com relação à lâmina armazenada na zona radicular (Larm), visualiza-se que o projeto 4 apresentou o maior valor $(11,79 \mathrm{~mm})$, seguido dos projetos 5, 3, 2 e 1 (11,18 $\mathrm{mm}, 10,62 \mathrm{~mm}, 10,48 \mathrm{~mm}$ e $9,48 \mathrm{~mm}$, respectivamente).

Relacionando-se a Lapl e Larm, podemos verificar que $57,04 \%, 80,86 \%, 77,63 \%, 62,98 \%$ e $81,01 \%$ da água aplicada pelos projetos $1,2,3,4$ e 5 respectivamente, ficam armazenadas na região radicular. Podendo-se inferir que a irrigação foi excessiva em todos os projetos, devido ao mau dimensionamento.

No que se refere à lâmina deficitária (Ldef), é possível afirmar que o projeto 1 apresentou a maior
Ldef (2,09 mm), seguido dos projetos 5, 2, 3 e 4 $(1,34 \mathrm{~mm}, 0,42 \mathrm{~mm}, 0,32 \mathrm{~mm}$ e $0,24 \mathrm{~mm}$, respectivamente), devido à baixa eficiência de aplicação de água que os projetos possuem.

Quanto à lâmina percolada (Lper), detecta-se que o projeto 3 apresentou a maior Lper $(4,58 \mathrm{~mm})$, seguido dos projetos $4,2,5$ e 1 (4,48 mm, 3,99 mm, 3,38 mm e $2,54 \mathrm{~mm}$, respectivamente). O que equivale a $33,48 \%, 23,93 \%$, $30,79 \%, 24,49 \%$ e $15,28 \%$ das lâminas aplicadas pelos projetos $3,4,2,5$ e 1 respectivamente, que são perdidas por percolação, isto indica que em $100 \%$ dos projetos de irrigação avaliados ocorrem perdas de água por percolação profunda, conforme está apresentado nas Tabelas 5 e 6.

Na Tabela 6 estão apresentados os resultados dos parâmetros técnicos: porcentagem de área adequadamente irrigada (Pad), eficiência potencial de aplicação de água (Epa), segundo Bernardo (1995), coeficiente de déficit $(\mathrm{Cd})$, perdas por percolação (Pper), eficiência de condução (Ec), eficiência de distribuição de projeto (EDpad), eficiência de irrigação para área adequadamente irrigada (Eipad) e eficiência de aplicação (Ea), referentes ao desempenho atual dos projetos de irrigação por aspersão convencional avaliados.

Pela Tabela 6, verifica-se que o projeto 4 apresentou a maior Pad $(76,66 \%)$, seguido dos projetos $1,2,3$ e $5(60,00 \%, 55,00 \%, 55,00 \%$ e $55,00 \%$, respectivamente). A Pad média foi de $60,33 \%$, isto indica que $60 \%$ das áreas irrigadas recebem uma quantidade de água igual ou maior que a IRN. Podendo-se inferir que todos os projetos avaliados apresentam uma Pad inferior ao valor preconizado pela literatura como o ideal em qualquer sistema de irrigação, que é de $80 \%$.

Observa-se na Tabela 6 que o projeto 2 apresentou a maior Epa Bernardo $(91,25 \%)$, seguido dos

Tabela 6. Porcentagem de área adequadamente irrigada (Pad), Eficiência potencial de aplicação de água (Epa), segundo Bernardo (1995), Coeficiente de déficit (Cd), perdas por percolação (Pper), Eficiência de condução (Ec), Eficiência de distribuição de projeto para área adequadamente irrigada (EDpad), Eficiência de irrigação para a área adequadamente irrigada (Eipad) e Eficiência de aplicação (Ea) dos projetos de irrigação por aspersão convencional avaliados.

\begin{tabular}{lcccccccc}
\hline Projeto & Pad $(\%)$ & Epa $_{\text {Bernardo }}(\%)$ & Cd $(\%)$ & Pper $(\%)$ & Ec (decimal) & EDpad $(\%)$ & Eipad $(\%)$ & Ea $(\%)$ \\
\hline 1 & 60,00 & 75,45 & 18,03 & 20,26 & 0,99 & 93,98 & 91,00 & 57,04 \\
2 & 55,00 & 91,25 & 3,85 & 33,73 & 0,99 & 95,02 & 91,85 & 80,80 \\
3 & 55,00 & 86,01 & 2,91 & 38,91 & 0,99 & 93,83 & 90,77 & 77,61 \\
4 & 76,66 & 81,56 & 1,96 & 29,34 & 0,99 & 87,51 & 84,63 & 62,97 \\
5 & 55,00 & 88,83 & 10,71 & 27,57 & 0,99 & 94,85 & 91,17 & 80,98 \\
Média & 60,33 & 84,62 & 7,49 & 29,96 & 0,99 & 93,04 & 89,88 & 71,88 \\
\hline
\end{tabular}


projetos 5, 3, 4 e $1(88,83 \%, 86,01 \%, 81,56 \%$ e $75,45 \%$, respectivamente), significando que a água infiltrou nas parcelas nestas proporções. E isto indica que o projeto 1 apresentou a maior perda de água por evaporação e arraste pelo vento $(24,55 \%)$, seguido dos projetos 4, 3, 5 e $2(18,44 \%, 13,99 \%, 11,17 \%$ e $8,75 \%$, respectivamente). Podendo-se deduzir que os valores da Epa Bernardo variaram de 75,45 a $91,25 \%$, com perdas por evaporação e arraste pelos ventos entre 8,75 e $24,55 \%$.

Devido às perdas de água por evaporação e arraste das partículas de água provocado pelo vento a lâmina aplicada não atendeu a demanda, ocasionando um coeficiente de déficit $(\mathrm{Cd})$ que variou entre 1,96 e $18,03 \%$. Pela Tabela 6 , visualiza-se que o projeto 1 apresentou o maior Cd $(18,03 \%)$, seguido dos projetos $5,2,3$ e $4(10,71 \%, 3,85 \%$, $2,91 \%$ e $1,96 \%$, respectivamente). O que corrobora os resultados obtidos por Costa (2006).

Quanto às perdas por percolação (Pper), nota-se que o projeto 3 apresentou a maior Pper $(38,91 \%)$, seguido dos projetos 2, 4, 5 e $1(33,73 \%, 29,34 \%$, $27,57 \%$ e $20,26 \%$, respectivamente). Podendo-se deduzir que $100 \%$ dos projetos avaliados apresentaram valores de perdas por percolação profunda superiores a $20 \%$, isto se deve ao fato de que os projetos avaliados possuem baixa uniformidade e eficiência de aplicação de água, apesar de possuírem uma eficiência de condução (Ec) média de 0,99. No que se refere à eficiência de distribuição de projeto para área adequadamente irrigada (EDpad) é possível verificar que o projeto 2 apresentou o maior valor $(95,02 \%)$, seguido dos projetos $5,1,3$ e $4(94,85 \%, 93,98 \%, 93,83 \%$ e $87,51 \%$, respectivamente). Esses valores indicam os percentuais de eficiência de distribuição de projeto incorporando o conceito de área adequadamente irrigada (80\%). Além disso, a EDpad indica que houve perda por percolação profunda, além ser um indicativo que a quantidade de água aplicada foi suficiente para atender a demanda hídrica, ou seja, a lâmina requerida de irrigação.

A eficiência de irrigação para a área adequadamente irrigada (Eipad) foi inferior a Edpad em todos os projetos avaliados, porque a Eipad combina os valores obtidos para uniformidade de aplicação de água, a adequação da irrigação e as perdas que normalmente ocorrem no sistema. Assim, a Eipad congrega os efeitos devidos às perdas por desuniformidade de aplicação, perdas por percolação, perdas por evaporação e deriva e as perdas na condução, representadas pelas eficiências de distribuição, aplicação e condução, respectivamente. Observa-se que o projeto 2 apresentou a maior Eipad $(91,85 \%)$, seguido dos projetos $5,1,3$ e $4(91,17 \%, 91,00 \%$, $90,77 \%$ e $84,63 \%$, respectivamente).

Quanto à eficiência de aplicação de água (Ea), verifica-se que o projeto 5 apresentou o maior valor $(80,98 \%)$, seguido dos projetos $2,3,4$ e 1 $(80,80 \%, 77,61 \%, 62,97 \%$ e $57,04 \%$, respectivamente). Podendo-se deduzir que $40 \%$ dos projetos avaliados apresentaram valores de Ea igual a $80 \%$. A eficiência de irrigação para a área adequadamente irrigada (Eipad) média foi de 89,88\% e a eficiência de aplicação (Ea) média foi de $71,88 \%$. Este valor demonstra que a lâmina aplicada foi superior à lâmina real, indicando que a irrigação foi excessiva. O que contradiz os resultados obtidos por Soares e Nascimento (1998), no sistema de irrigação por aspersão do Perímetro Irrigado Barreiras, Petrolândia - PE, onde a eficiência média de irrigação do sistema foi de $54,27 \%$.

De forma geral, em todos os projetos, foram encontrados baixos valores de eficiência de aplicação de água (Tabela 6), ou seja, valores abaixo do valor recomendado pela literatura para sistemas de irrigação por aspersão convencional, que é de $85 \%$. Podem-se obter altos índices de eficiência empregando-se um dimensionamento correto do projeto, equipamentos adequados e um manejo racional da água. Os resultados obtidos nas avaliações dos projetos indicam que, além de falhas na decisão sobre quando irrigar há também a adoção de tempo de irrigação maior que o necessário, levando a lâminas percoladas muito elevadas. Essas distorções podem ser observadas na Figura 1.

Em todos os projetos de irrigação, a quantidade de água que a planta necessita é menor que a lâmina média aplicada, para o período avaliado, conforme pode ser visto na Figura 1. Observa-se que o projeto 4 apresentou o maior excesso de água aplicada $(55,61 \%)$, seguido dos projetos $1,3,2$ e 5 (43,65\%, $25,05 \%, 19,01 \%$ e $10,22 \%$, respectivamente). O que corrobora os resultados obtidos por Soares e Nascimento (1998). As diferenças entre as lâminas requeridas e aplicadas são devido ao inadequado manejo de irrigação. Deve-se, portanto, adotar métodos de estimativa e controle da necessidade e aplicação de água a fim de evitar desperdícios. Neste contexto, as práticas de manejo são extremamente importantes para todos os sistemas de irrigação, contribuindo para uma irrigação eficiente, atendendo às 

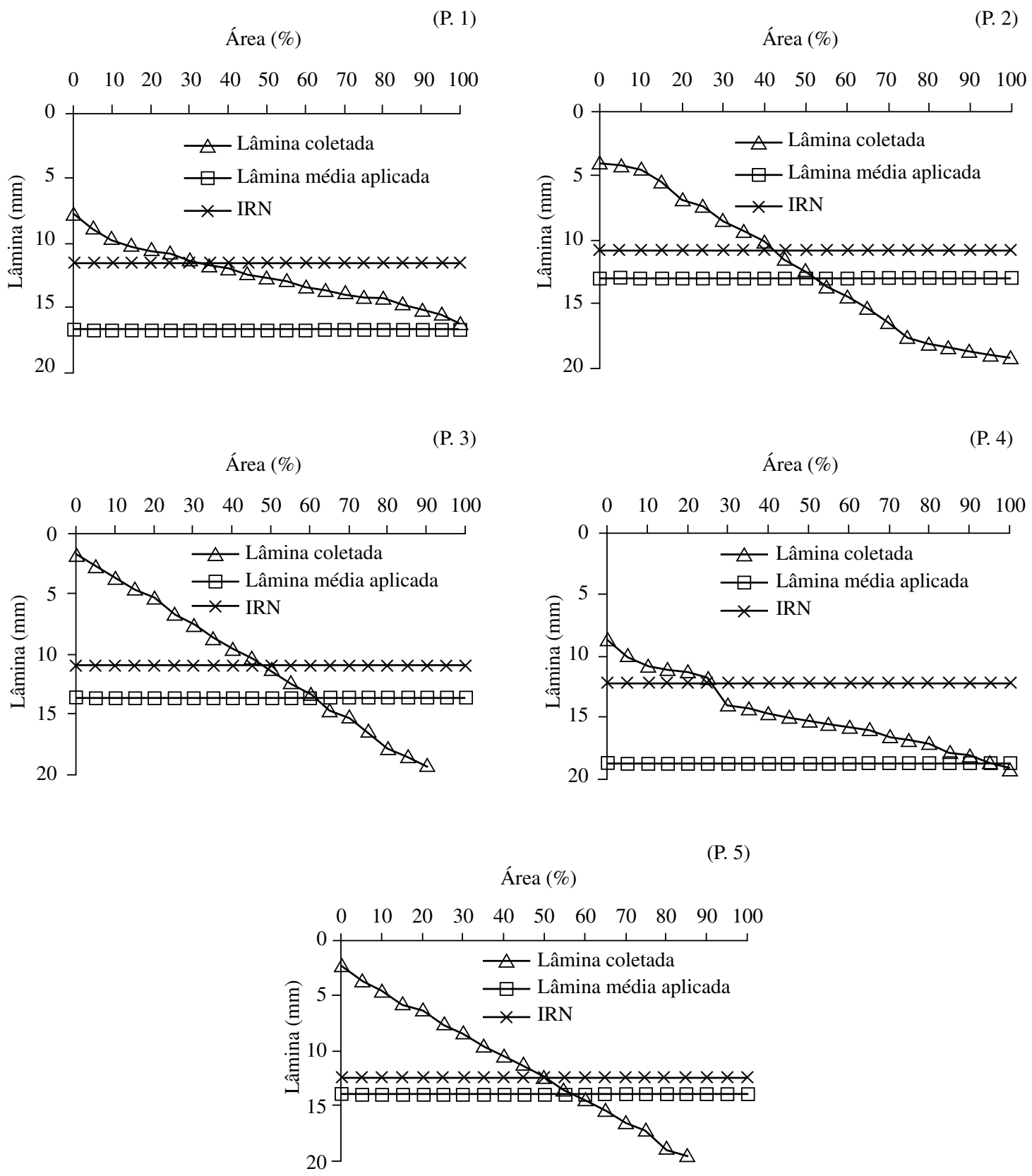

Figura 1. Percentual de área irrigada em cada Projeto (P.) avaliado em função das lâminas: coletada, aplicada e real necessária.

necessidades da cultura, o que, segundo Mantovani; Bernardo; Palaretti (2009) pode beneficiar uma cultura de várias maneiras, entre elas, aumentando sua produtividade e permitindo maior eficiência no uso de fertilizantes.

\section{Conclusões}

Conclui-se que $60 \%$ dos projetos avaliados apresentam baixa uniformidade de aplicação de água.
Em todos os projetos de irrigação, a lâmina aplicada no período avaliado foi superior à lâmina real necessária à planta.

Em 100\% dos projetos avaliados os valores de perdas por percolação profunda foram superiores a $20 \%$, sendo que a lâmina percolada variou de 2,54 a 4,58 mm.

A eficiência de aplicação (Ea) variou de 52,04\% a $80,98 \%$, ficando abaixo de $85 \%$, preconizado pela literatura como o mínimo aceitável. 


\section{Referências Citadas}

Alencar, C.A.B. de.; Cunha, F. F. da.; Ramos, M.M.; Soares, A.A.; Pizziolo, T. de A.; Oliveira, R.A. de.

2007 Análise da automação em um sistema de irrigação convencional fixo por miniaspersão. Engenharia na Agricultura, Viçosa, MG, v. 15, n. 2, 109-118, Abr./Jun.

Bernardo, S.

1995 Manual de Irrigação. 5 ed. Viçosa, MG: UFV, Imprensa Universitária. 596p.

Bernardo, S.; Soares, A.A.; Mantovani, E.C. 2006 Manual de Irrigação. 8 ed. Viçosa, MG: UFV. 625 p.

Bonomo, R.; Bonomo, D.Z.; Secundino, M.V.; Pezzopane, J.R.M. 2008 Uniformidade de irrigação por aspersão fixa em café conilon no norte capixaba. In: XVIII Congresso Nacional de Irrigação e Drenagem, 2008, São Mateus. Anais de Trabalhos Completos (CD-ROM). São Mateus: ABID, 2008, n. 1588.

Christiansen, J.E.

1942 Irrigation by sprinkling. Berkley: University of California. $124 \mathrm{p}$.

Costa, M.B. da.

2006 Avaliação da irrigação por pivô central na cultura do café (Coffea canephora L.) e na cultura do mamoeiro (Carica papaya L.) no município de Pinheiros-ES. 2006. 89p. Tese (Doutorado em Agronomia). Escola Superior de Agricultura Luiz de Queiroz, Piracicaba.

Criddle, W.D.; Davis, S.; Pair, C.H.; Shockley, D.G. 1956 Methods for evaluating irrigation systems. Washington DC: Soil Conservation Service-USDA, 1956. 24 p.

EMBRAPA-Empresa Brasileira de Pesquisa Agropecuária. 1999 Centro Nacional de Pesquisa de Solos. Manual de métodos de análise de solos. 2. ed. Rio de Janeiro. 412 p.

EMBRAPA-Empresa Brasileira de Pesquisa Agropecuária. 2006 Sistema Brasileiro de Classificação de Solos. 2. ed. Rio de Janeiro: EMBRAPA Solos. 306 p.

Fancelli, A.L.; Dourado Neto, D.

2000 Ecofisiologia e fenologia. In: Fancelli, A. L.; Dourado Neto, D. Produção de milho. Guaiba: Agropecuária, 2000. p. 21-54.
Keller, J.; Bliesner, R.D.

1990 Sprinkle and trickle irrigation. New York: Van Nostrand Reinhold. $652 \mathrm{p}$.

Manfron, P.A.; Bacchi, O.O.S.; Dourado Neto, D.; Pereira, A.R. 2003 Modelo da profundidade efetiva do sistema radicular na cultura de milho em função de graus-dia acumulados. Revista Brasileira de Agrometeorologia. Santa Maria, v. 11, n. 2, p. 327-332.

Mantovani, E. C.

2001 Avalia: Programa de Avaliação da Irrigação por Aspersão e Localizada. Viçosa, MG: UFV.

Mantovani, E.C.; Bernardo, S.; Palaretti, L.F.

2009 Irrigação: princípios e métodos. 3. ed., atual. e ampl. Viçosa, MG: UFV. 355 p.

Martins, C.A. da S.; Oliveira, C.M.R.; Pandolfi, F.; Mendonça, G.P. de.; Passos, R.R.; Reis, E.F. dos.; Griffo, M.

2007 Alterações na densidade do solo de um latossolo vermelho-amarelo sob diferentes coberturas vegetais. In: XI Encontro Latino Americano de Iniciação Científica, 2007, São José dos Campos. Anais de Trabalhos Completos (CD-ROM). São José dos Campos: UNIVAP. p. 2238-2240.

Silva, C.A. da; Silva, C.J. da.

2005 Avaliação de uniformidade em sistemas de irrigação localizada. Revista Científica Eletrônica de Agronomia, Garça, n. 8, dez.

Soares, J.M.; Nascimento, T.

1998 Avaliação técnica do sistema de irrigação por aspersão do perímetro irrigado Barreiras. Revista Brasileira de Engenharia Agrícola e Ambiental, v. 2, n. 2, p. 136-141.

Souza, E.A.M. de; Souza, P.C. de.; Boas, M.A.V.

2008 Avaliação do desempenho de sistemas de irrigação por aspersão convencional fixo e gotejamento em vila rural. Irriga, Botucatu, v. 13, n. 1, p. 47-62, Jan./Mar.

Wilcox, J.C.; Swailes, G.E.

1947 Uniformity of water distribution by some under tree orchard sprinklers. Scientific Agriculture, v. 27, n. 11, p. $565-583$. 